\title{
Un punto de partida para una reflexión sobre la interdisciplinariedad
}

\author{
Wisberto Navarro Salcedo \\ Departamento de Psicopedagogía
}

El presente trabajo se propone reflexionar sobre la ciencia, fundamentar unos presupuestos generales y contribuir al enriquecimiento del diálogo interdisciplinariofian necesario ahora para tener claridad sobre la misión de la universidad y, derroteros para orientar la reestructuración de la misma.

El supuesto que está a la base de ésta exposición es el que se puede lograr una adecuada fundamentación de la actividad cientifica,si a ello contribuye la filosofía, sin desconocer los desarrollos de otros campos del sabcr. Esta introducción nos ubica frente a problemas epistemológicos que deben ser abordados.

Desde sus comienzos la filosofía había pretendido tener un conocimiento fundamental, más "verdadero" de la realidad. Por esto se la llamó "ciencia primera". Desde dicho planteamiento las ciencias particulares conservaron cierto tipo de dependencia con respecto a la filosofía.

Pero en la modernidad y en el momento en que las ciencias cobraron una aparente autonomía con relación a la reflexión filosófica y comenzaron a desarrollarse por si mismas en la autocomprensión de su estatuto teórico, en el empleo de sus métodos, en la solución de sus problemas y en la aplicación de sus descubrimientos, pareció darse una cspecie de competencia entre la filosofía y las ciencias. Competencia que persiste todavia. Se suele creer por la mayoría de las personas que la filosofía es algo esotérico cuyo aporte al desarrollo de la sociedad y al sentido de la vida de los hombres es más bien negativo. De otro lado se evidencia el aporte cada vez más definitivo de la ciencia y de la técnica al desarrollo de la humanidad.

Esta tensión entre ciencia y filosofia no puede resolverse de manera simplista. Es preciso confrontar los paradigmas dejando que el debate los fortalezca o los derribe. El problema se tratará aqui de manera crítica.

El punto de partida de la reflexión crítica sobre el proceso actual de la ciencia debe reconocer que la práctica científica no puede entenderse en forma autónoma y aislada, sino que está inmersa en una totalidad más amplia que es la totalidad social, la cual condiciona la actividad de la comunidad científica y por lo tanto del investigador a partir de su experiencia precientifica, histórica, social y política. De aquí se derivan varias consecuencias para una fundamentación metodológica de las ciencias. (1)

La reflexión epistemológica de Habermas, concebida como teoría dialéctica de la sociedad, parte de una reconstrucción de la historia entendida como proceso de autoconstitución del individuo y la especie humana. Dicho proceso en la doble relación del hombre con 
la naluraleza y del hombre en sus relaciones sociales, se va constituyendo en torno a tres medios fundamentales de socialización: el trabajo, el lenguaje y la interacción social.

Por medio del trabajo el individuo y la especie entran en contacto con la naturaleza exterior a ellos y la someten con fines de supervivencia. El trahajo implica tanto la humanización de la naturalcza como la naturalización del hombre. El trabajo obedece así al interés técnico de lograr una emancipación del hombre frente a su entorno natural, y la ciencia considerada como la primera fuerza productiva ocupa un lugar destacado en éstc proceso.

El lenguaje es el medio simbólico que posibilita la designación de cosas y sucesos, asi como la formación de la propia identidad y la apropiación de la identidad común a los grupos humanos. Aquí el lenguaje está a poy ado en la dimensión de un saber práctico, (Concepto que se aclarará más adelante), y es la expresión de un yo ejecutor de acciones comunicativas. Es en la comunicación libre como se concreta un interés práctico,entendiendo por él la posibilidad de participar en la construcción de su propia historia.

La interacción social constituyc el espacio propio de las relaciones de los individuos entre sí. El interés que lo guia es el de la emancipación de toda forma de opresión. (2)

En su obra "Conocimiento e interés", Habermas elabora una critica a la absolutización del modelo positivista de la ciencia, precisando el papel que deben asumir las distintas ciencias dentro de cada uno de los procesos básicos de afirmación de la especie humana antes descritas y concretando los presupuestos teóricos-metodológicos a que obedece cada una de ellas en su desarrollo especifico. Con éste fin distingue tres tipos de ciencias:

Las ciencias empírico-analíticas que combinan reglas para la elaboración de teorias con sus condiciones de control. A istas teorias se adicionan conjuntos de proposiciones de las cuales se deducen hipótesis susceptibles de control empírico. Este saber permite el pronóstico con la finalidad de su aplicación técnica.

Las ciencias histórico-hermenéuticas tienen otro marco metodológico. La validez de sus proposiciones no se basa en la diferenciación entre la construcción de hipótesis y el diseño de experiencia para su comprobación, sino en las reglas de la hermenéutica que rigen la interpretación de los textos. Estas ciencias permiten una apropiación de la cultura y las tradiciones sobre las cuales se acumula la identidad de los pueblos y orientan desde éste fondo común las posibles acciones de los individuos.

Finalmente las ciencias crítico-sociales buscan determinar cuando la legalidad establecida en el ámbito de lo social oculta relaciones de dependencia y dominación sedimentadas ideológicamente. El contexto que fija la valide $z$ de sus proposiciones es la autorreflexión, guiada por el interés de emancipar al hombre de toda forma de opresión y que las ciencias sociales críticas comparten con la filosofía.

Con éstos fundamentos podemos aclarar tres aspectos que surgen dentro de ésta perspectiva: En primer lugar, la noción restringida de la práctica al interior de las llamadas ciencias naturales, según la cual aquella se entiende como observación controlada, en condiciones reproducibles por cualquier investigador y sin ingerencia al-
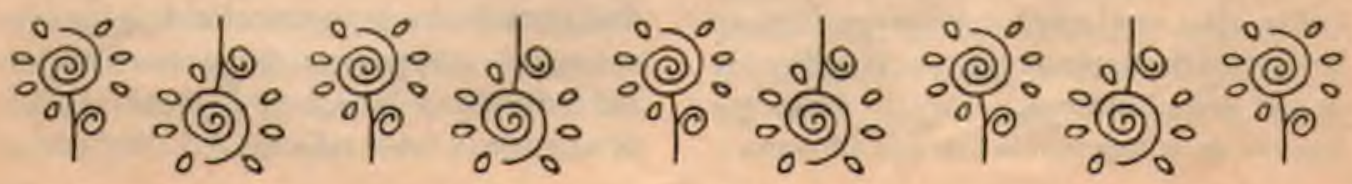

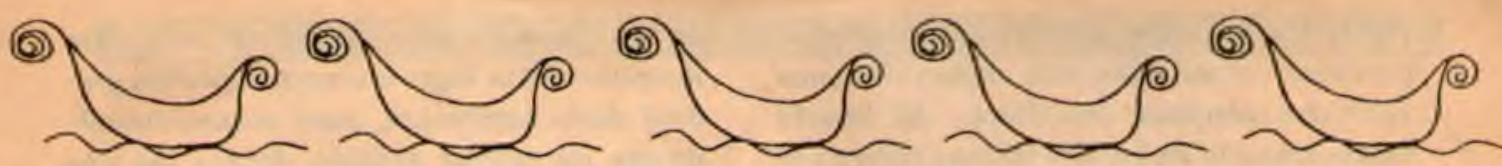

guna de la subjetividad, se revela como insuficiente. En efecto, es en el contexto de una experiencia acumulada precientíficamente, donde tiene origen los problemas, conceptos y orientaciones centrales de la práctica científica. Este concepto es mucho más rico, en cuanto incluye la experiencia e historicidad y necesidades vitales de los individuos que hacen ciencia.

En segundo lugar la práctica científica Se reconoce como una práctica histórica, la comunidad cientifica se desenvuelve dentro de un proceso evolutivo, determinado por múltiples factores económicos, culturales y políticos. Es aquí frente a problemas históricos donde los investigadores asumen compromisos prácticos con la transformación de la socicdad en que viven. Es importante tratar de clarificar la cuestión del compromiso práctico. Así como hay un interés por la predicción, que preside el interés técnico propio de las disciplinas empírico-analiticas, hay también un interés científico, serio y disciplinado, que busca comprender las situaciones para orientar la práctica social, la práctica personal, la práctica de la comunidad científica. Carlos E. Vasco al respecto escribe:

"Debemos afirmar que si hay un interés de hacer ciencia, que más que la predicción yel control, busca la orientación y la ubicación de la praxis. . .

A éste interés lo llama la escuela de Frankfurt "interés práctico". Si uno empieza por mencionar la palabra "práctico", generalmente está desorientando al auditorio desde el principio, porque cuando uno habla de "cosas prácticas" está hablando de cosas muy fáciles de manejar, que sean muy útiles y que funcionen bien: "es una grabadora muy práctica". Entonces es claro que la sola consideración de la palabra "práctico" puede llevar en una dirección equivocada. Se trata es de ubicar la praxis social y personal dentro de la historia y de orientar esa praxis: por lo tanto, ese interés por más que sea teórico no está alejado de la praxis: tan poco alejado esta, que Habermas, decidió llamarlo "interés práctico", a pesar de que todo el que oiga la palabra "práctico" la entienda mal". (3)

Esta larga cita nos debe conducir a reflexionar sobrc el hecho de que la práctica cientifica se reconoce como una práctica histórica; pero no se debe entender la historia de la manera como se ha enseñado, lo histórico no son solo las casas de museo y los retratos de los próceres.

"Lo histórico significa también sentirse haceg de la historia en ese momento. Por eso se trata de ubicar y orientar la práctica actual de los grupos y las personas dentro de esa historia que estamos haciendo y empezamos a hacer y de la que todavia somos más bien victimas que actores". (4)

En tercer lugar la práctica cientifica se revela como práctica sociopolítica a la cual Habermas se identifica con un interés emancipatorio, es decir la actividad científica no se fundamenta únicamente en el momento de las decisiones metodológicas y de las operalizaciones concretas en el campo de la ciencia, como parece afirmarlo la noción del método científico. La actividad científica tiene su raiz en la totalidad social a la cual esta ligado el investigador y se halla condicionado a los intereses sociopolíticos a los cuales pertenece.

La necesidad de reflexionar sobre este tema es importante para iniciar cualquier trabajo de interdisciplinariedad en la Universidad. Existen muchas prevenciones y descalificaciones apriori sobre el trabajo 
cientifico de otras persionas que es preciso procurar entenderlas para desarrollar una actividad conjunta fructífera. El interés emancipatorio de las disciplinas críticas es desacreditado por las personas que tienen su actividad en las disciplinas empíricoanalíticas e histórico-hermenéuticas. Se lee: Las personas que manejan muy bien el estilo histórico-hermenéutico dicen también que las disciplinas empírico-analíticas son solo instrumentos que ellos necesitan para hacer la verdadera ciencia, y que las disciplinas críticas son mera "ideología". Sin embargo desde el punto de vista crítico es perfectamente explicable porque estas personas tienen que desacreditar este estilo de hacer ciencia, mientras que ellos no pueden ver desde el punto de vista más estrecho, que éste estilo si es cientifico; tienen que verlo como no cientifico, pues es una amenaza a su propia manera de hacer ciencia". (5)

Hay que poseer la capacidad de vislumbrar un tipo de actividad científica que no hay porque descalificar como no científico, que no tiene un interés solo especulativo, simplemente de ver lo que hay ahí, describirlo, explicarlo y comprenderlo, sino que busca develar lo oculto con lo cual nos encontramos atados en la praxis histórica y busca encontrar la manera de transformarla.

\section{Algunas Conclusiones}

Una reflexión sobre la ciencia debe destacar el carácter relativo de la apropiación técnica y la comprensión práctica con respecto a los procesos de la totalidad social y es con referencia a esa totalidad como adquiere su razón de ser.

Dicha totalidad genera tres tipos de intereses que producen actividades cientificas diferentes y que de ninguna manera sc pueden descalificar entre sí.

Es conveniente aclarar que no son lo mismo la ciencia empirica positiva y el positivismo. Aquella constituye un momento necesario para le desenvolvimiento. de la especie humana. Mediante su acción instrumental se logra una emancipación gradual de la naturaleza, pero solamente adquiere un mayor sentido dentro de una comprensión dialéctica de la sociedad y la historia. En el momento en que se absolutiza el interés técnico se cae en el positivismo y se anula con ello toda capacidad crítica y reflexiva.

Por último, es importante hallar la relación entre los tres estilos citados, conocer hacia donde apunta cada saber, para hacer un trabajo interdisciplinario serio. Pues, no puede decirse que el estilo empírico-analítico tiene que ver so con el trabajo, que el estilo histórico-hermenéutico solo con el lenguaje y que el estilo critico-social solo con el poder. La práctica de las disciplinas guiadas por el interés técnico, que son la mayor parte de la ciencia histórica-hermenéutica sin tener grandes bases empírico-analíticas, está buscando una ubicación puramente ideológica o cubriendo su posición ideológica previa con un ropaje científico. La persona que quiere hacer ciencia crítica, (emancipadora), sin tener un dominio de los otros dos estilos, probablemente no está siendo un verdadero crítico, arriesgándose así a que su bien intencionada crítica, por ignorar la seriedad cientifica de los estilos anteriores, caiga siempre en la esterilidad anarquizante.

\section{Notas Bibliográficas}

1) HOYOS, Guillermo. Significado de la reflexión epistemológica para la investigación - acción. Revista Ciencia, Tecnología y Desarrollo, Colciencias, Volumen 4, No. 3, Bogotá, JulioSeptiembre, 1980. Pág. 277-292.

(2) HABERMAS, Jurgen. Cifr. La reconstrucción del materialismo histórico. Editorial Taurus, Madrid, 1981

(3) VASCO, Carlos E. Tres estilos de trabajo en las ciencias sociales. Documentos ocasionales num. 54, cinep, 2 edición, Bogotá, 1990. Pág. 19.

(4) Ibidem, pág. 20.

(5) Ibidem, pág. 22. 